\title{
Some Haemato-Biochemical Values in White New Zealand Rabbits
}

\author{
Saad M. Shousha ${ }^{1}$, Mohamed A. Mahmoud ${ }^{2 *}$, Khalid Hameed ${ }^{3}$ \\ ${ }^{I}$ Department of Physiology, Faculty of Veterinary Medicine, Moshtohor, Benha University, Egypt. \\ ${ }^{2}$ Department of Physiology, Faculty of Veterinary Medicine, New valley, Assuit University, Egypt \\ 3Department of Zoology, Faculty of Sciences, Omar Al-Mukhtar University, Al-Baida, Libya.
}

\begin{abstract}
Haematological and biochemical parameters are important and reliable media used to monitor, evaluate health and nutritional status of animals. This studywas conducted toestablish the normal rangesof haematologicaland somebiochemical parameters inboth male and female rabbits and to determine thegender effect on these values. Blood and urine samples from a total of 44 New Zealand white rabbits were investigated. The haematological parameters were determined in whole blood samples, while biochemical parameters were determined in serum and urine samples. Normal values of these parameters were determined and statistical comparisons between male and female rabbits were performed.Current study results revealed that haematologicalandbiochemicaldata were identicalin both male and female animals and statistically no significant differences were found for the parameters analysed except, RBCs count,haemoglobin concentration $(\mathrm{Hb})$,haematocrit value (Hct), white blood cell (WBC) count, neutrophils \%, lymphocytes \%, monocytes\%, basophils\% and platelets count. It was concluded that defining the normal values of the given haematological and biochemical parameters in New Zealand white rabbits would be valuable for both researchers and clinicians as they may beconsidered as useful baseline values for domestic rabbit populations.
\end{abstract}

Keywords: New Zealand rabbit, Haematological, Biochemical, Normal parameters.

\section{Introduction}

Rabbits are being used as a valuable source of animal protein in rural communities, as well as for scientific research in academic institutions. The need to increase livestock production as a mean of alleviating the awesome shortage of animal protein is very vital to humanity [1]. The demand for protein of animal origin in some developing countries is greater than its supply. Therefore, the grave shortage in dietary animal protein in these countries demands extra effort to be directed to livestock that are prolific and have short gestation interval such as rabbit. Delicious high protein content, low calories, and fat content meat of domestic rabbit are extra reasons for the aching demands that encourage rearing of domestic rabbits,easier availability, high fertility, feeding and housing features make the New Zealand white rabbits to be widely used in laboratory works $[2,3]$. Besides the use of the rabbits as a protein source,the increasing of rabbit popularity increased the demand for veterinary services for these animal. So hematological and biochemical reference values aiding in diagnosis and prognosis of rabbit disease became crucial [4]. Haematological parameter is a reliable mean for health and nutritional status evaluation [5]. Breed, gender, age, pregnancy, circadian rhythm, disease conditions, environmental, physical or nutritional stressful conditions are factors affecting haematological and biochemical parameters $[3,6,7,8,9,10]$. All these conditions can be monitored through biochemical and haematological parameters examination that allow the detection of numerous metabolites and extra constituents of blood $[6,8]$. The rabbits have become widely used for laboratory and domestic purposes, this ensures the value and the importance of studies on this animal species $[10,11,12,13]$. Numerous studies had been done on the blood parameters of various domestic animals, nevertheless extra biochemical and haematological values of New Zealand white rabbits are still needed. These reference values are of a great importance in evaluation of rabbit health conditions and provides valuable information for researchers and clinicians $[7,8,14,15,16]$.So the present study was carried out to determine the normal values of some haematological, biochemical parameter in serum and urine of both male and female New Zealand white rabbits and to define the gender effect on these parameters.

\subsection{Experimental animals}

\section{Materials and Methods}

Atotal of 44 New Zealand white rabbits (22 males and 22 female); age $8-12$ months and of 3.5 to $4.5 \mathrm{~kg}$ weight were used in the current study. Each rabbit was physically examined and unhealthy ones (feverish, with nasal or ocular discharge, diarrhoea, ear mites, atypical lung sounds, or large wounds) were excepted from the study. Before the beginning of the experiment, the experimental animals were treated against endo/ectoparasites and coccidiosis for one month and their average body weight $(3.5-4.5 \mathrm{~kg}$ ) was kept uniform as possible. The animals were individually kept in cages in appropriate laboratory conditions $\left(23 \pm 2^{\circ} \mathrm{C}, 12\right.$-h dark 
and light cycles). Commercial pellet (Purina ${ }^{\circledR}$ Rabbit Chow $^{\mathrm{TM}}$ ) contained a minimum of $86 \%$ dry matter, minimum $14 \%$ crude protein, maximum $16 \%$ cellulose, maximum $10 \%$ crude ash and minimum $2400 \mathrm{kcal} / \mathrm{kg}$ metabolic energy was given ad libitum to the rabbits. Drinking water was providedby automaticnipples. Feed and Environment adaptation period ( 2 weeks) were allowed to the experimental animalsbefore samples collection. All procedures were performed consistent with the Physiological Society's guidelines for experimental animal's care.

\subsection{Collection of samples}

According to the described method, $24 \mathrm{~h}$ urine sample was collected between 9:00-11:00 a.m. from each rabbit through metabolic cages, using graduated glasses; The urine samples were centrifuged at $3000 \mathrm{rpm}$ for 10 minutes then the obtained supernatant was kept at $-20^{\circ} \mathrm{C}$ until assayed. Moreover, $5 \mathrm{ml}$ of blood was obtained from each rabbit by marginal ear vein puncture using a 22-gauge sterile needle. For haematological analysis, the blood samples were expelled gradually into tubes containing K3-EDTA (Ethylene DiamineTetra acetic acid), the tubesweredirectly cappedand gentlymixedby frequent inversion. The samplesweredirectly transportedtothelaboratory within 3 hat $4{ }^{\circ} \mathrm{C}$ for further analysis. Whereas,for biochemical analysis; non anticoagulated blood samples were collected in sterile tube, centrifuged for $10 \mathrm{~min}$ at $3000 \mathrm{rpm}$; the serum was obtained and kept at $-20^{\circ} \mathrm{C}$ until analysis

\subsection{Haematologicaland BiochemicalStudies}

Bloodsampleswith K3-EDTAanticoagulantwere used forthedeterminationofhaematological parameters: which include RBCs count, haemoglobin concentration $(\mathrm{Hb})$, haematocrit value (Hct), mean corpuscular volume (MCV), mean corpuscular haemoglobin $(\mathrm{MCH})$, mean corpuscular haemoglobin concentration (MCHC), white blood cell (WBC) count, neutrophils \%, lymphocytes \%, monocytes \%, eosinophils \%, basophils \%, platelets count). Anticoagulated blood samples Analyses were performed via CellDYN3500HaematologyAnalyser (Abbott DiagnosticDivision, SantaClaraCA). As statedbythemanufacturer'soperationmanual Suggested settings andadjustmentfor rabbit haematologywereapplied.

Serum contents of glucose, albumin, total protein $(\mathrm{Tp})$, globulin, nitrite, calcium $(\mathrm{Ca})$, chloride $(\mathrm{Cl})$, phosphorus $(\mathrm{P})$, potassium $(\mathrm{K})$, sodium $(\mathrm{Na})$, creatinine, total bilirubin $(\mathrm{Tb})$, blood urea nitrogen $(\mathrm{BUN})$, activities of $\gamma$-glutamyl transferase (GGT), aspartate aminotransferase (AST), alkaline phosphatase (ALP) and alanine aminotransferase (ALT)were measured.

Also, urine contents of glucose, protein, creatinine, creatinine clearance, GGT, urea, potassium (K), sodium $(\mathrm{Na})$, chloride $(\mathrm{Cl})$, nitrite, were measured. Urine contents of glucose, protein, creatinine, urea and GGT were evaluated spectrophotometrically (Photometer 5010®-Boehringer Mannheim) following the procedures defined in the commercial test kits (Biolabo, Italy), while the urine and serum $\mathrm{Cl}^{-}, \mathrm{Na}^{+}$and $\mathrm{K}^{+}$analyses were done on an ion selective device (ISE®-Medica). Urine glucose, protein, creatinine, urea, $\gamma$-glutamyl transferase (GGT), $\mathrm{Cl}$, nitrite, $\mathrm{Na}$, and $\mathrm{K}$ levels were evaluated at the urine supernatant.

Nitrite levels of serum and urine samples were determined by Griess Reagent method at $540 \mathrm{~nm}$ on ELISA device (ELISA reader ${ }^{\circledR}$-DAS) using nitric oxide kit (Griess Reagent System, Cat No: G2930 ${ }^{\circledR}$-Promega), as defined in commercial test kits. Creatinine clearance was calculated using the formula for creatinine clearance (Kaneko et al., 1997).

\subsection{Statistical analysis}

Comparison between female and male rabbits were done using independent sample t- test through SPSS software (Ver. 11.5) at a significant level $P<0.05$. and $P<0.001$. Other statistical parameter as Means \pm SEM, Maximum and minimum normal values were also determined.

\section{Results}

In the present study, the normal values of some haematological, biochemical parameter in serum and urine of both male and female New Zealand white rabbits were displayed. The arithmetic means, standard error of means, maximum and minimum values of blood parameters haematologically revealed very highly significant differences $(\mathrm{P}<0.001)$ regarding $\mathrm{RBC}$ count, $\mathrm{Hb}$, Hct, monocytes, basophils and platelet count in males $(5.71 \pm 0.50,14.82 \pm 0.90,46.64 \pm 2.40,0.50 \pm 0.30,0.20 \pm 0.10$ and $482.80 \pm 22.10$; respectively) compared to females $(4.31 \pm 0.32,10.45 \pm 0.45,40.14 \pm 2.11,1.00 \pm 0.24,0.40 \pm 0.10$ and $577.30 \pm 32.19$; respectively). Likewise, in male a significant elevation $(\mathrm{P}<0.05)$ was observed regarding WBC count $(13.90 \pm 1.23)$ and lymphocytes \% (68.60 \pm 5.80$)$ compared with females ( $10.44 \pm 1.08$ and $64.40 \pm 3.84$; respectively). But, there was a significant decrease $(\mathrm{P}<0.05)$ in neutrophils $\%$ in males $(30.10 \pm 3.40)$ versus females $(34.50 \pm 2.42)$. On the other hand, no significant variation for the other blood parameter measured as $\mathrm{MCH}$, MCV, MCHC, eosinophils \% (Table1). Also, no variation ( $\mathrm{P} \mid>0.05)$ was reported in the serum(glucose, $\mathrm{Tp}$, albumin, globulin, $\mathrm{Ca}, \mathrm{P}, \mathrm{Na}, \mathrm{K}, \mathrm{Cl}$, creatinine, nitrite BUN, GGT, Tb, AST, ALT and ALP) and urine biochemical parameters (glucose, protein, creatinine, creatinine clearance, urea, nitrite, GGT, $\mathrm{K}, \mathrm{Na}, \mathrm{Cl}$ ) among males and females (Table 2,3). 


\section{Discussion}

The current study was performed to determine the reference standards of some haematological, serum and urine biochemical parameters for both female and male white New Zealand rabbit species and to examine the gender effect on these factors. Mainly, the blood parameter is a dependable and essential mean used to evaluate and monitor nutritional and health status of animals [5].The haematological examination provides the chance to examine numerous metabolites and other constituents that aid in detecting the stress conditions, which could be nutritional, environmental or physical[6]. Moreover, the blood parameters mostly offer data on inflammation, necrosis, numerous infections of visceral organs and stress factors[2, 8, 17]. Identifying biochemical and haematological reference values of rabbits provides valuable data for investigators in their studies, and clinicians for regarding the health condition of animals in clinical practice $[7,8,10,15,16]$. Breed, gender, age, feeding, disorders, stress, circadian rhythm, pregnancy and environmental conditions are factors that influence the blood parameters $[3,7,8,9,10]$. Additionally, WBCs count seldom elevated due to infection in rabbit but it is more related to blood collection methods and various stress factors [8, 15, 18]. Rabbits kept alone possess higher WBCs count than those fed in groups [12].

In the study presented here, some of haematological parameters (RBC, Hb, Hct, MCHC, WBC, PLT) of the white New Zealand rabbits were within the normal range values previously recorded by $[2,10,16,18,19$, 20], Moreover the results were consistent with [10] who proved that the blood parameters showed significant increase in RBCs count, Hct, Hb, WBCs count and Lymphocytes \%, and significantly lower neutrophils, monocytes \%, basophils and platelets counts value among males than females. The increase in male erythrocytesattributed to the androgenic effect that increased erythropoietin production [21] .

Regarding the biochemical parameters of serum, defining these parameters provides an important information about visceral organs damage in rabbits, particularly for the liver and the kidneys[2,8, 10, 18]. Total protein, Glucose, creatinine, albumin, BUN, P, Ca, K, Na and $\mathrm{Cl}$ levels for the white New Zealand rabbits determined in the current study were within the reference values range reported in previous studies $[8,10,15,22$, 23]. The significantly higher protein and albumin levels among males may be ascribed to the androgens anabolic effect. Though, the other biochemical parameters of serum showed no significant difference among female and male rabbits.

Earlier studies reported that the elevated blood glucose levels among rabbits are generally due to various stress factors $[8,14,18]$. Moreover, blood glucose levels were reported to be lesser than the serum or plasma glucose levels [11]. The serum glucose levels determined in the current study were higher than those reported in some studies[2,18] and lower than that of [15]. Hypothetically, this variance may be caused by the variations in some factors as blood collection methods, housing conditions and stress. However, [24] and[10], under the same condition of this study, showed no significant difference for serum glucose levels between female and male animals. Concerning $\mathrm{Tb}$ values, both male and female rabbits showed a normal ranges of values matches those previously described by previous investigators [8, 10, 14]. They were higher than that of [20] and [22]. Serum GGT activity was higher than those found in former studies [8, 11, 20, 22, 23]. AST activity was close to the reported levels in some preceding studies [10, 20], but lower than the observed levels in others [8, 15, 23]. ALT activity was lesser than the reported values in some prior studies [8, 15, 18, 20, 22, 23]. ALP activity was close to the reported levels by other researchers $[8,14]$, but lesser than the levels obtained by others $[15,25]$. The activity of serum ALP originates from both bone and liver varied according to the age, where younger individuals showed a higher serum ALP levels, this is because of the rapid bone growth [26]. The decreased serum ALP activity in the existing study might be accredited to the differences in growth period and age of the rabbits.This study revealed no significant variation in the serum nitrite levels among males and females. This finding agreed with the result of [10]. However, [27] reported a higher nitrite level of 8.93 \pm 1.09 $\mu \mathrm{mol} / \mathrm{L}$.

Defining the urine biochemical parameters provides important information on renal functions and electrolyte disturbance in rabbits. However, limited data describing normal biochemical parameters of rabbit urinewas available. This fact makes it to be one of the current study aims to find out reference biochemical urine values for both sex in white New Zealand rabbits.Earlier studies $[8,10,18,28]$ found that trace amounts of protein and glucose in rabbit urine is normal. [29] showed that healthy rabbits urine contains $0.15-0.52 \mathrm{mg} / \mathrm{kg}$ protein a day. The increases urine glucose and protein levels indicated impaired renal functions while, transient increase was exercise and stress induced [18]. Urine GGT rise is an earlier indicator and one of the markers considered for renal functions impairment $[8,10,28]$.

While conducting this study reference ranges values for urine parameters such as protein, glucose, creatinine, urea, GGT, nitrite, $\mathrm{Na}, \mathrm{K}, \mathrm{Cl}$ and creatinine clearance in rabbits were rare. In other available literature, no statistical difference in the urine parameters like protein, glucose, creatinine, urea, GGT, nitrite, $\mathrm{Na}, \mathrm{K}, \mathrm{Cl}$ and creatinine clearance was found between female and male white New Zealand rabbits. Hence, describing the normal values of these parameters in both female and male rabbits in the current study is remarkable. 
The observed variation in the present study result compared with some earlier studies may be related to the different approaches that were used to calculate the respective variables. and the manual approach that relied more on the technician/researcher to conduct the tests Narrower ranges suggest precise estimates and of greater value for monitoring the health status. Instead, narrower standard deviation indicates that these differences in biochemical and haematological values could be caused by nutritional, environmental factors and hormonal among each experimental animal group. Therefore, a specific analysis and comparison between different units has to be planned and performed for better understanding the usefulness of haematology and clinical chemistry for assessing the health and welfare of rabbits. So more investigation is needed.

\section{V.Conclusion}

In conclusion, the recorded results can provide a set of normal values of haematological parameters, serum and urine biochemical parameters that can be helpful for both researchers and clinicians and may therefore be considered useful baseline values for domestic rabbit populations.

\section{References}

[1] D Fielding, Rabbits. The Tropical Agriculturalist, CTA Macmillan Education Ltd Macmillan Publishers London, UK,1991, 16-17.

[2] R Jurcik, K. Suvegova, E. Hanusova, P. Massanyi, L. Ryban, P. Chrenek, Evaluation of Haematological, Biochemical and Histopathological Parameters of Transgenic Rabbits, Journal of Veterinary Medicine Series A, 54,2007, 527-531.

[3] E Jeklova, L. Leva, P. Knotigova, M. Faldyna, Age-related changes in selected haematology parameters in rabbits, Research in Veterinary Science, 86,2009, 525-528.

[4] N Burnett, M. K., M. K.S., H. R.B., B. G., C. M., An investigation into haematological and serum chemistry parameters of rabbits in Trinidad, World Rabbit Science, 14,2006, 175 - 187.

[5] A R. Gupta, R.C. Patra, M. Saini, D. Swarup, Haematology and Serum Biochemistry of Chital (Axis axis) and Barking Deer (Muntiacus muntjak) Reared in Semi-Captivity, Veterinary Research Communications, 31,2007, 801-808.

[6] F A. Aderemi, Effects of replacement of wheat bran with cassava root sieviate supplemented or unsupplemented with enzyme on the haematology and serum biochemistry of pullet chicks, tropical journal of animal science, 7,2004, $147-153$.

[7] C A. Chineke, A.G. Ologun, C.O.N. Ikeobi, Haematological Parameters in Rabbit Breeds and Crosses in Humid Tropics, Pakistan Journal of Biological Sciences, 9,2006, 2102-2106.

[8] A Melillo, Rabbit Clinical Pathology, Journal of Exotic Pet Medicine, 16,2007, 135-145.

[9] A S. Abdel-Azeem, A.M. Abdel-Azim, A.A. Darwish, E.M. Omar, Haematological and biochemical observations in four pure breeds of rabbits and their crosses under Egyptian environmental conditions, World Rabbit Science, 18,2010, 103-110.

[10] C Özkan, A. Kaya, Y. Akgül, Normal values of haematological and some biochemical parameters in serum and urine of New Zealand White rabbits, World Rabbit Science, 20,2012,

[11] C D. Hewitt, D.J. Innes, J. Savory, M.R. Wills, Normal biochemical and hematological values in New Zealand white rabbits, Clin Chem, 35,1989, 1777-1779.

[12] G C. Fuentes, J. Newgren, Physiology and clinical pathology of laboratory New Zealand White Rabbits housed individually and in groups, Journal of the American Association for Laboratory Animal Science, 47,2008, 35-38.

[13] S Zhao, K. Wei, Q. Yu, Y. Li, F. Cheng, Y. Wang, P. Yang, J. Fan, E. Liu, General topic: applications of transgenic rabbits in biomedical research - based on literature search, World Rabbit Science, 18,2010, 159-167.

[14] D A.W. Lepitzki, A. Woolf, Hematology and serum chemistry of cottontail rabbits of southern illinois, Journal of Wildlife Diseases, 27,1991, 643-649.

[15] T d.O. Silva, L.C. Kreutz, L.J.G. Barcellos, J. Borella, A.B. Soso, C. Souza, Reference values for chinchilla (Chinchilla laniger) blood cells and serum biochemical parameters, Ciência Rural, 35,2005, 602-606.

[16] I Archetti, C. Tittarelli, M. Cerioli, R. Brivio, G.L. Grilli, A., Serum chemistry and haematology values in commercial rabbits. preliminary data from industrial farms in northern Italy, In proceed of 9th World Rabbit Congress, 2008, 10-13.

[17] MA. Betancourt-Alonso, A. Orihuela, V. Aguirre, R. Vázquez, F.I. Flores-Pérez, Changes in behavioural and physiological parameters associated with Taenia pisiformis infection in rabbits (Oryctolagus cuniculus) that may improve early detection of sick rabbits, World Rabbit Science, 19,2011,

[18] J R. Jenkins, Rabbit Diagnostic Testing, Journal of Exotic Pet Medicine, 17,2008, 4-15.

[19] N Cetin, A. Bilgili, G. Eraslan, . Koy, A. , Effect of fluoride application on some blood parameters in rabbits, Erciyes University Journal of Health Sciences, 13,2004, 46-50.

[20] F L. Tavares, M.C.C. Sousa-e-Silva, M.L. Santoro, K.C. Barbaro, I.M.M. Rebecchi, I.S. Sano-Martins, Changes in hematological, hemostatic and biochemical parameters induced experimentally in rabbits by Loxosceles gaucho spider venom, Human \& Experimental Toxicology, 23,2004, 477-486.

[21] M Kerr, Veterinary Laboratory Medicine, Clinical Biochemistry and Haematology, Oxford, 2nd Ed, Blackwell Publications, 2002,

[22] E Yazar, Çöl, R., Konyalığlu, S., Birdane, Y.O., Elmas, M., and Baş, A.L., Effects of vitamin E and prednisolone on biochemical and haematological parameters in endotoxaemic New Zealand White Rabbits, Bulletin- Veterinary Institute in Pulawy, 48,2004, $105-108$.

[23] M Elmas, E. Yazar, K. Uney, A. Karabacak, Pharmacokinetics of Flunixin after Intravenous Administration in Healthy and Endotoxaemic Rabbits, Veterinary Research Communications, 30,2006, 73-81.

[24] S Yamada, T. Ito, T. Tamura, M. Shiomi, Age-Related Changes in Serum/Plasma Biochemical Parameters of WHHLMI Rabbits, Experimental Animals, 53,2004, 159-163.

[25] V Wicher, K. Wicher, R. Gruhn, D.A. Pragay, S. Durham, M. Case Gould, Biochemical, hematologic, and histopathologic studies in rabbits intrarectally inseminated, Aids Research, 1,1983, 299-307.

[26] JJ. Kaneko, J.W. Harvey, M.L. Bruss, Clinical Biochemistry of Domestic Animals, 5th Ed., Academic Press, California-USA, 1997,

[27] S. Haghjooyjavanmard, M. Nematbakhsh, M. Soleimani, The Effect of Hypercholesterolemia on Serum Vascular Endothelial Growth Factor and Nitrite Concentrations in Early Stage of Atherosclerosis in Rabbits, Pakistan Journal of Nutrition, 8,2009, 86-89.

[28] C Özkan, The effects of nitric oxide donor (L-arginine) and nitric oxide synthase inhibitors (Aminoguanidine, L-NAME) in experimentally induced nephrotoxicity in rabbits, Thesis, PhD, University of Yuzuncu Yil,2009,

[29] M Türkmen, S. Kavukcu, H. Islekel, S. Sarioğlu, H. Akhunlar, N. Gökden, A. Güre, Urinary N -acetyl- $\beta$ - D -glucosaminidase activity in rabbits with experimental hypercalciuria, Pediatric Nephrology, 11,1997, 481-484. 
Table 1: Normal values of some haematological parameters in white New Zealand rabbit's serum.

\begin{tabular}{|c|c|c|c|c|}
\hline \multirow[t]{2}{*}{ Blood parameters } & \multicolumn{2}{|c|}{ Male $($ No. $=22)$} & \multicolumn{2}{|c|}{ Female (No.=22) } \\
\hline & Mean \pm SEM & Range & Mean \pm SEM & $\overline{\text { Range }}$ \\
\hline $\operatorname{RBC}\left(\times 10^{6} / \mathrm{mm}^{3}\right)$ & $5.71 \pm 0.50^{* * *}$ & $4.11-7.20$ & $4.31 \pm 0.32$ & $3.22-5.98$ \\
\hline $\mathrm{Hb}(\mathrm{g} / \mathrm{dL})$ & $14.82 \pm 0.90^{* * *}$ & $10.45-16.81$ & $10.45 \pm 0.45$ & $7.57-13.45$ \\
\hline Het $(\%)$ & $46.64 \pm 2.40^{* * *}$ & $38.41-51.50$ & $40.14 \pm 2.11$ & $34.68-47.54$ \\
\hline $\operatorname{MCV}$ (fl) & $67.52 \pm 3.40$ & $58.42-72.8$ & $62.50 \pm 1.22$ & 55.57- 66.89 \\
\hline MCH (pg) & $23.71 \pm 1.00$ & $19.45-27.83$ & $22.11 \pm 1.01$ & $18.55-25.52$ \\
\hline $\operatorname{MCHC}(\%)$ & $33.44 \pm 0.81$ & $28.54-36.29$ & $30.24 \pm 0.33$ & $25.52-34.61$ \\
\hline WBC $\left(\times 10^{3} / \mathrm{mm}^{3}\right)$ & $13.90 \pm 1.23^{*}$ & $9.32-15.84$ & $10.44 \pm 1.08$ & $8.45-13.34$ \\
\hline Neutrophils (\%) & $30.10 \pm 3.40^{*}$ & $26.57-34.69$ & $34.50 \pm 2.42$ & $25.81-36.55$ \\
\hline Lymphocytes (\%) & $68.60 \pm 5.80^{*}$ & $59.55-73.53$ & $64.40 \pm 3.84$ & $56.46-68.57$ \\
\hline Monocytes (\%) & $0.50 \pm 0.30^{* * *}$ & $0.50-0.90$ & $1.00 \pm 0.24$ & $0.50-1.20$ \\
\hline Eosinophils (\%) & $0.60 \pm 0.20$ & $0.40-0.90$ & $0.60 \pm 0.15$ & $0.40-0.90$ \\
\hline Basophils (\%) & $0.20 \pm 0.10^{* * *}$ & $0.00-0.30$ & $0.40 \pm 0.10$ & $0.00-0.30$ \\
\hline PLT $\left(\times 10^{3} / \mathrm{mm}^{3}\right)$ & $482.80 \pm 22.10^{* * *}$ & $95.00-1079.00$ & $577.30 \pm 32.19$ & $79.00-1167.00$ \\
\hline
\end{tabular}

* Significant at $\mathrm{P} 0<0.05$ and $* * *$ highly significant at $\mathrm{P}<0.001$

Abbreviation.RBCs: red blood cells count, Hb:haemoglobin, HCT: haematocrit, MCHC:mean corpuscular haemoglobin concentration, MCV: mean corpuscular volume, $\mathrm{MCH}$ :mean corpuscular haemoglobin, WBCs: white blood cell count, PLT: platelets count, SEM: standard error of the mean.

Table 2: Normal values of some biochemical parameters in white New Zealand rabbit's serum.

\begin{tabular}{|c|c|c|c|c|}
\hline \multirow{2}{*}{$\begin{array}{l}\text { Biochemical } \\
\text { parameters }\end{array}$} & \multicolumn{2}{|c|}{ Male (No.=22) } & \multicolumn{2}{|c|}{ Female $($ No. $=22)$} \\
\hline & Mean \pm SEM & Range & Mean \pm SEM & Range \\
\hline Glucose $(\mathrm{mmol} / \mathrm{L})$ & $8.32 \pm 0.31$ & $3.22-11.01$ & $6.97 \pm 0.40$ & $2.70-9.45$ \\
\hline Tp (g/dl) & $7.10 \pm 0.50$ & $4.19-10.65$ & $6.20 \pm 0.30$ & $2.42-9.13$ \\
\hline Albumin (g/dl) & $3.60 \pm 0.30$ & $2.11-3.98$ & $3.10 \pm 0.31$ & $2.01-3.81$ \\
\hline Globulin (g/dl) & $2.80 \pm 0.40$ & $1.94-3.10$ & $2.40 \pm 0.35$ & $1.50-2.95$ \\
\hline Nitrite $(\mu \mathrm{M})$ & $5.62 \pm 0.57$ & $0.96-11.39$ & $5.59 \pm 0.49$ & $1.50-13.54$ \\
\hline $\mathrm{Ca}(\mathrm{mmol} / \mathrm{L})$ & $3.35 \pm 0.08$ & $2.01-4.01$ & $3.40 \pm 0.21$ & $2.55-4.43$ \\
\hline$P(\mathbf{m m o l} / \mathrm{L})$ & $1.37 \pm 0.06$ & $1.01-1.96$ & $1.25 \pm 0.04$ & $1.07-1.85$ \\
\hline $\mathrm{Na}(\mathrm{mmol} / \mathrm{L})$ & $148.31 \pm 0.84$ & $136.63-151.45$ & $145.45 \pm 0.75$ & $132.56-149.81$ \\
\hline $\mathrm{K}(\mathrm{mmol} / \mathrm{L})$ & $4.91 \pm 0.06$ & $3.23-5.78$ & $4.08 \pm 0.04$ & $3.03-5.12$ \\
\hline $\mathrm{Cl}(\mathrm{mmol} / \mathrm{L})$ & $115.50 \pm 0.72$ & 100.09-119.56 & $114.6 \pm 0.85$ & $101.43-118.37$ \\
\hline Creatinine (mmol/L) & $0.10 \pm 0.00$ & $0.01-0.15$ & $0.11 \pm 0.00$ & $0.01-0.15$ \\
\hline BUN (mmol/L) & $11.31 \pm 0.54$ & $7.23-16.65$ & $11.70 \pm 0.44$ & $6.54-15.98$ \\
\hline Tb $(\mu \mathrm{mol} / \mathrm{L})$ & $3.60 \pm 0.15$ & $1.1-4.98$ & $3.20 \pm 0.13$ & $0.86-5.16$ \\
\hline GGT (U/L) & $16.78 \pm 1.87$ & $10.56-24.68$ & $14.63 \pm 1.13$ & $8.39-21.53$ \\
\hline $\operatorname{AST}(\mathbf{U} / \mathrm{L})$ & $10.98 \pm 1.01$ & $6.14-18.57$ & $10.12 \pm 0.89$ & $7.34-17.52$ \\
\hline $\operatorname{ALT}(\mathbf{U} / \mathbf{L})$ & $7.80 \pm 0.32$ & $5.56-10.44$ & $7.20 \pm 0.12$ & $4.79-9.93$ \\
\hline $\operatorname{ALP}(\mathbf{U} / \mathbf{L})$ & $18.04 \pm 1.02$ & 13.29-27.74 & $17.11 \pm 0.86$ & $12.63-24.89$ \\
\hline
\end{tabular}

Abbreviation. Tp: total protein, BUN: urea nitrogen, Tb: total bilirubin, GGT: $\gamma$-glutamyltransferase, AST:aspartate aminotransferase, ALT: alanineaminotransferase, ALP: alkaline phosphatase,

SEM:Standard error of the mean.

Table 3: Normal values for some biochemical parameters in New Zealand white rabbits' urine.

\begin{tabular}{|l|cccc|}
\hline \multirow{2}{*}{ Biochemical parameters } & \multicolumn{2}{|c|}{ Male (No.=22) } & \multicolumn{2}{c|}{ Female (No.=22) } \\
\cline { 2 - 5 } & Mean \pm SEM & Range & Mean \pm SEM & Range \\
\hline Glucose $(\mathbf{m m o l} / \mathbf{L})$ & $0.41 \pm 0.08$ & $0.02-1.09$ & $0.39 \pm 0.07$ & $0.00-0.97$ \\
\hline Protein $(\mathbf{g} / \mathbf{L})$ & $4.01 \pm 0.60$ & $0.00-12.87$ & $4.23 \pm 0.95$ & $0.00-14.7$ \\
Creatinine (mmol/L) & $12.38 \pm 2.24$ & $1.71-22.27$ & $14.43 \pm 1.65$ & $5.36-30.88$ \\
\hline Creatinine Clearance (mL/min kg) & $1.57 \pm 0.29$ & $0.12-7.52$ & $1.26 \pm 0.14$ & $0.46-3.11$ \\
\hline Urea $(\mathbf{g} / \mathbf{2 4 h})$ & $1836 \pm 208$ & $362-1804$ & $1365 \pm 157$ & $280-3472$ \\
\hline GGT $(\mathbf{U} / \mathbf{L})$ & $28.34 \pm 2.16$ & $13.68-56.39$ & $32.78 \pm 2.83$ & $16.83-64.72$ \\
\hline Nitrite $(\boldsymbol{\mu M M})$ & $7.47 \pm 0.54$ & $3.98-16.78$ & $6.96 \pm 0.35$ & $2.48-13.27$ \\
\hline Na $(\mathbf{m m o l} / \mathbf{L})$ & $62.12 \pm 3.98$ & $37.11-112.92$ & $55.36 \pm 4.72$ & $30.44-107.37$ \\
\hline K $(\mathbf{m m o l} / \mathbf{L})$ & $219.45 \pm 11.76$ & $36.67-354.23$ & $189.15 \pm 17.63$ & $32.56-338.92$ \\
\hline Cl $(\mathbf{m m o l} / \mathbf{L})$ & $194.63 \pm 12.69$ & $25.58-350.52$ & $164.96 \pm 16.93$ & $22.58-319.67$ \\
\hline
\end{tabular}

Abbreviation.GGT: $\gamma$-glutamyl transferase

Saad M. Shousha. "Some Haemato-Biochemical Values in White New Zealand Rabbits." IOSR Journal of Agriculture and Veterinary Science (IOSR-JAVS) 10.7 (2017): 40-44. 